\title{
ALEITAMENTO MATERNO E AS CRENÇAS ALIMENTARES
}

Sueli Mutsumi Tsukuda Ichisato ${ }^{1}$

Antonieta Keiko Kakuda Shimo ${ }^{2}$

Ichisato SMT, Shimo AKK. Aleitamento materno e as crenças alimentares. Rev Latino-am Enfermagem 2001 setembro-outubro; 9(5):70-6.

A hipogalactia tem levado ao desmame precoce. As crenças e os tabus influenciam a alimentação materna durante a lactação. 0 presente estudo tem como objetivo identificar lactogogos regionais utilizados como suporte do aleitamento materno (AM), pautados nos tabus e crenças. Trata-se de um estudo de caso utilizando a análise de prosa ${ }^{(12)}$. Alimentar-se ou não de certos alimentos, ter vivenciado a amamentação, as crenças transmitidas por familiares e médicos, crescimento e desenvolvimento da criança foram os fatores que estimularam o AM na nossa pesquisa

PALAVRAS CHAVE: hipogalactia, aleitamento materno, desmame, amamentação

\section{BREASTFEEDING AND NUTRITIONAL BELIEFS}

Hypogalactia has been one of the reasons that lead mothers to early weaning. Beliefs and taboos influence breastfeeding during lactation. This study aims at identifying regional lactagogues used as a support to breastfeeding based on taboos and beliefs. It is a case report which uses prose analysis ${ }^{(12)}$. The findings show that feeding oneself with certain types of food or not, having experienced breastfeeding, beliefs transmitted by family members and physicians and the child's growth and development were factors which stimulated breastfeeding.

KEY WORDS: hypogalactia, weaning, breastfeeding

\section{LACTANCIA MATERNA Y LAS CREENCIAS ALIMENTARIAS}

La hipogalactacemia ha sido uno de las razones que han llevado a las madres al destete precoz. Las creencias y los tabúes influyen en la alimentación materna durante la lactancia. El presente estudio tiene como objetivo identificar lactogogos regionales utilizados como soporte del alimento materno (AM), basados en los tabues y las creencias. Se trata de un estudio de caso utilizando el análisis de prosa ${ }^{(12)}$. Alimentarse o no de ciertos alimentos, haber vivido la lactancia, las creencias transmitidas por familiares y médicos, crecimiento y desarrollo del niño fueron los factores que estimularon el AM en nuestra investigación.

PALABRAS CLAVES: hipogalactacemia, lactancia materna, destete

\footnotetext{
${ }^{1}$ Enfermeira, Pós-Graduanda do Curso de Mestrado do Departamento Materno Infantil e Saúde Pública da Escola de Enfermagem de Ribeirão Preto da Universidade de São Paulo, docente da disciplina de Assistência de Enfermagem em Situações Clínicas II, do Curso de Graduação em Enfermagem do Centro Universitário Barão de Mauá, e-mail: sichisato@hotmail.com; ${ }^{2}$ Enfermeira, Professor Doutor aposentada da Escola de Enfermagem de Ribeirão Preto da Universidade de São Paulo, docente do Departamento de Enfermagem da UNICAMP
} 
INTRODUÇÃO

A lactação é uma das maneiras mais eficientes de atender os aspectos nutricionais, imunológicos, psicológicos e 0 desenvolvimento de uma criança no seu primeiro ano de vida ${ }^{(1-2)}$.

Pudemos constatar através de várias literaturas que a hipogalactia (insuficiência lactacional), é uma das razões primordiais que levam ao desmame precoce ${ }^{(1-5)}$.

Além disto, as crenças e os tabus influenciam no aleitamento materno, principalmente, no tocante à alimentação materna durante a lactação ${ }^{(5)}$.

A questão do aleitamento materno, não é somente biológica, mas é histórica, social e psicologicamente delineada. A cultura, a crença e os tabus têm influenciando de forma crucial a sua prática.

Os enfermeiros necessitam adentrar na comunidade estudando sua cultura, comportamentos, pensamentos e atos arraigados, para obter dados que possam ser utilizados para a criação de políticas de saúde na área materno-infantil voltadas para a real dimensão dos problemas da mulher e da criança ${ }^{(5)}$.

Devemos nos lembrar que o ser humano que atendemos tem a sua subjetividade, a sua tradição cultural, os seus hábitos, tabus e crenças fundamentados em seus antepassados. Esquecemonos de respeitá-los, ditando-lhes normas e condutas, até modelos de saúde impostos, querendo que estes cumpram o "protocolo".

Tendo em vista a importância do aleitamento materno para a criança e a mulher, entendemos que o sucesso da promoção da amamentação, também está relacionada a programas educativos de diversas naturezas e vimos com clareza, a valorização do hábito cultural ligado a esta prática.

Assim, sensibilizadas com a problemática da hipogalactia e a importância dos aspectos culturais no aleitamento materno, temos como objetivo deste trabalho: identificar os lactogogos/galactogogos regionais utilizados como suporte do aleitamento materno e tentar desvelar em que estão embasados. Objeto que faz parte das orientações de um programa de incentivo ao aleitamento governamental ${ }^{(4)}$, que diz respeito ao aumento da produção de leite da lactante, indicando o uso de galactogogos ou lactogogos locais (alimento ou bebida que, segundo crenças locais, aumentam a produção do leite materno).

A questão calórica, o aporte nutricional, a ingestão de alimentos de qualidade e quantidade são enfatizados em muitos estudos, porém não há explicações quanto aos tipos de alimentos serem indicados como galactogogos.

\section{FUNDAMENTAÇÃO TEÓRICA}

A fim de entender como a questão cultural influencia no modo de agir do ser humano, em especial no ato de amamentar, buscamos fundamentação nos conceitos culturais de crença, fé, mito e tradição para compreender a transmissão cultural das crenças alimentares.

Crença ${ }^{(6)}$ é "convicção íntima; opinião adotada com fé e convicção". Fé( ${ }^{(7)}$ sinônimo de "confiança". Mitos ${ }^{(8)}$ são "representações de fatos ou personagens reais, exagerada pela imaginação popular, pela tradição, etc". Tradição ${ }^{(9)}$, quer dizer "transmissão oral de lendas, fatos, etc., de idade em idade, geração em geração. Conhecimento ou prática resultante de transmissão oral ou de hábitos inveterados". As palavras em negrito foram resgatadas, com intuito de trabalharmos com a transmissão cultural.

O homem recebe dois tipos de herança ao nascer: a herança cultural e a genética. A cultural transmite costumes, hábitos, valores e idéias, enquanto que a genética, as características físicas ${ }^{(5)}$.

Neste sentido o fator cultural constrói o saber do homem. As crenças e os tabus fazem parte desta construção como herança sociocultural, determinando diferentes significados do aleitamento materno para a mulher. A decisão de amamentar ou não o seu bebê, alimentar-se ou não de determinados alimentos no puerpério depende do significado que a mulher atribui a esta prática.

\section{METODOLOGIA}

Optamos pela linha qualitativa utilizando o Estudo de Caso como método de pesquisa. Este tipo de estudo envolve um ou vários casos que são estudados através do tempo, fazendo uso de inúmeros métodos de coleta de dados.

A questão da complexidade do estudo de caso determinado pelos suportes teóricos é visto, como "um enfoque a-histórico, reduzido às características culturais de um meio específico no qual se insere a unidade em exame, de natureza qualitativafenomenológica"(10).

Analisamos e buscamos compreender as variáveis históricas de transmissão de conhecimento da amamentação, o desenvolvimento e o cuidado dispensado, especificamente, nos alimentos utilizados durante 0 aleitamento materno.

O gravador foi usado como instrumento para a coleta de dados, porque as informações coletadas de forma escrita pelo pesquisador não são tão fidedignas quando comparadas aos dados coletados por intermédio de um gravador ${ }^{(11)}$. Este instrumento eletrônico facilita ao investigador retornar à fonte registrada, para checar as informações, obter novas conclusões e reestudar a análise elaborada. Assim, a coleta de dados foi feita através de uma entrevista semi-estruturada com o emprego de um gravador.

O universo desse estudo de caso foi constituído por três 
mulheres que tinham amamentado, com grau de parentesco (netaM1; mãe-M2 e avó-M3) e que estavam em condições de participar da pesquisa respondendo as questões de uma entrevista semiestruturada e morassem na cidade de Ribeirão Preto.

A primeira abordagem foi feita individualmente, através do telefone fornecido pela sogra da entrevistada $n^{0} 1$ (M1), que posteriormente nos passou os números dos telefones de M2 e M3. Todas foram questionadas se gostariam de participar da pesquisa. Realizamos orientações acerca do estudo mediante a justificativa, 0 objetivo, e a relevância do estudo e marcado uma entrevista em suas residências. Neste dia marcado reorientamos e solicitamos consentimento verbal* ${ }^{*}$ para que a entrevista fosse gravada. Na qual obtivemos autorização

Para a análise dos dados utilizamos a técnica de análise de prosa, que permite detectar o significado contido nas falas. Desta forma os dados qualitativos auxiliam na apreensão da complexidade e multidimensionalidade dos fenômenos naturais; na compreensão das relações entre o contexto, ações e os indivíduos e nos construtos difíceis de serem quantificados como a criatividade e o pensamento crítico $^{(12)}$.

Foram construídos sistemas de categorias para a análise dos dados, identificando-os como temas e tópicos. 0 tema é tido como uma idéia e o tópico um assunto, na qual o tema envolve um nível maior de abstração que o tópico ${ }^{(12)}$.

Após transcrição das entrevistas, fizemos várias leituras e disto retiramos temas e tópicos.

\section{ANÁLISE E DISCUSSÃO DOS DADOS}

Esta unidade temática I, A VIVÊNCIA FAMILIAR DE ALEITAMENTO MATERNO, surgiu pós análise da resposta dada, quanto a importância de ter visto a mãe amamentar ou não. Podemos inferir ancoradas no suporte teórico que, aquela que amamentou reproduziu 0 ato de amamentar vivenciado.

Em nossa revisão bibliográfica constatamos que a determinação sociocultural, sobrepõe-se à determinação biológica, que é tomada de forma consciente por um pequeno número de pessoas, e que tal processo é insuficiente para se explicar um comportamento coletivo. $O$ aleitamento materno deixa de ser instintivo e biológico tornando-se "um comportamento social e mutável, conforme as épocas e os costumes" ${ }^{\prime(13)}$. Desta forma, o aleitamento materno ou a recusa, raramente, é um ato individual e consciente, estando preso à aprovação do seu grupo social ${ }^{(13-14)}$. Nesta análise elegemos a vivência como tópico.
Vivência

O discurso das entrevistadas demonstra claramente 0 posicionamento sociocultural (tradição) e a importância da vivência para o sucesso no aleitamento materno: Vi, da mais nova.... (M1); Já, as vizinhas minhas, ninguém dava mamadeira... (M3)

Quanto a unidade temática II, CRENÇA EM LACTOGOGOS, a análise foi feita frente ao questionamento: se a entrevistada acreditava (crença) na existência de algum alimento ou produto (lactogogos ou galactogogos) que aumentava a produção de leite da mulher que amamenta.

Através das falas abaixo poderemos relacionar à nossa unidade temática. Que aumenta? Alimentação, né...(M1); Sabia que fubá dá bastante leite? (M3)

Dessa unidade temática extraímos quatro tópicos: alimentos considerados lactogogos, quem transmitiu, validação do lactogogos e quando utilizou o lactogogo.

\section{Alimentos considerados lactogogos}

O uso de galega officinalis e vitaminoterapia, foram citados como lactogogos ${ }^{(3,13)}$. Há relatos de que antigamente as folhas do algodoeiro eram empregadas sob a forma de chá pelas pretas americanas. Neste período, coincidentemente os criadores de vacas leiteiras utilizavam torta de caroços de algodão à forragem para aumentarem a produção de leite. Esta foi a primeira correlação encontrada entre os animais (nutriz $x$ vaca leiteira) ${ }^{(3)}$.

Os chineses utilizavam-se de uma "mistura de gordura de porco, grão-de-bico, sopa de lulas e cabeças de camarão, com vinho doce feito de arroz glutinoso adicionado de insetos" ${ }^{\text {(15); }}$; enquanto que lactogol ou galega officinalis, lactifero, galactogeno, vinho Biogalênico e a cerveja Guiness eram mencionados, como produtos lactogênicos ${ }^{(13)}$, sem contudo explicar como seria a ação dos elementos acima citados.

A metoclopramida tem sido usada quando ocorre a inibição da lactação. Este medicamento é tido como um potente estimulador para a liberação da prolactina e conseqüentemente promove a produção do leite. Este mecanismo ocorre quando a metoclopramida age competitivamente inibindo a dopamina, um neurotransmissor, que suprime a liberação da prolactina ${ }^{(16)}$. O Plasil (metoclopramida) é o nome comercial deste medicamento no Brasil.

Na nossa vivência, também encontramos com freqüência queixas de hipogalactia, por parte das puérperas. Muitas vezes elas deixavam de comer certos alimentos por acreditarem, que esses secam ou diminuem a produção do leite. Às vezes dão ênfase na

* Pesquisa realizada em domicílios por livre e espontânea vontade dos pesquisados. A autorização foi feita verbalmente e gravada respeitando todos os preceitos éticos 
ingestão de alimentos que consideram lactogênicos, como a canjica,

a sopa de fubá, a água inglesa, a cerveja preta, o arroz doce, a canja, a água e o leite.

Na comunidade de Itapuá (PA), as mulheres acreditavam que durante a lactação tudo que comiam passava para o leite materno e muitas vezes fazia mal à criança. Os mais antigos ordenavam às lactantes não ingerissem determinados alimentos, restringiam a ingestão de algumas frutas e introduziam de forma precoce outros alimentos, e isto era respeitado. Como galactogogos as mulheres faziam uso de muito líquido, mingau de arroz, caldo de galinha, caldo de feijão, caldo de peixe, caldo de carne, açaí, água inglesa e colocar a criança para sugar. Faziam uso de recursos convencionais como passar o suor do pote de água, passar pente fino, passar o leite da árvore da fruta-pão e passar folha de mato nas mamas ${ }^{(5)}$.

Em termos nutricionais, é referenciado que a manutenção da lactação com ingestões energéticas e nutricionais mais baixas que as recomendadas é possível, e até sem aumento calórico, em relação à dieta da mulher não grávida, não lactante. Isto não implica, evidentemente, em não aumentar a ingestão de alimentos, ao contrário, sugere a importância do papel nutricional dos períodos anterior e posterior à gestação, no desempenho lactacional. É enfatizada a dieta, durante a gravidez, no que se refere aos alimentos essenciais e promotores do leite materno ${ }^{(15)}$.

Portanto recomenda-se que a mulher lactante receba, através de sua alimentação, grande quantidade de água, glícides, prótides, lípides, sais minerais e vitaminas, elementos que serão utilizados para a formação do leite, com a finalidade de não desfalcar suas reservas orgânicas ${ }^{(17)}$.

A lactação acarreta no organismo materno uma demanda similar à da gestação. Após o nascimento da criança, o alimento começa a ser produzido pelas glândulas mamárias, como o substituto sangüíneo para a criança; com o desenvolvimento do bebê, a alimentação da mãe também deve ser aumentada, e ajustada para oferecer alimentação ao seu lactente ${ }^{(18)}$.

Refeições intermediárias durante a lactação são recomendadas. Os líquidos devem ser tomados em abundância para reposição da água secretada no leite ${ }^{(19)}$.

Quanto a composição, é observado que a dieta materna e o estado nutricional pouco influenciam sobre o conteúdo de macro nutrientes (carboidratos, proteínas e lipídios) e também sobre a concentração de energia no leite materno. No entanto, a quantidade pode diminuir se não houver "matéria-prima" disponível para a glândula mamária, sem que haja alteração significativa quanto a sua composição ${ }^{(20)}$.

Um dos fatores que pode influenciar na decisão das mulheres a adotar ou não o leite materno como alimento para seus filhos, nos primeiros meses de vida, depende do aporte nutricional da lactante. Mulheres que acreditam ter alimentação insuficiente, sentem-se incapazes de produzir leite e amamentar seus filhos ${ }^{(6)}$.

A situação difere no que diz respeito a micro nutrientes (vitaminas e minerais), uma vez que estes estão diretamente influenciados pelo estado nutricional da mãe, para que esteja presente no leite materno ${ }^{(20)}$

As mulheres que participaram do nosso estudo mencionaram alimentos de qualidade, uso de medicamento (Plasil), ingestão de muito líquido (M1) e uma das entrevistadas (M2) demonstrou a importância do apoio social e a M3 discorreu sobre alimentos que acreditava (mito, fé, crença) aumentar o leite da mulher: ...fruta, aquele remédio também,... ...É Plasil, é bastante suco... ...bastante leite......muito líquido......Sopa, fubá... ...mais carne branca do que vermelha... ...bastante líquido.......couve também é bom, queijo... ...goiaba......sabe essa goiabada? Eu dissolvia ela no leite e tomava muito... ...chá mate também... ...o nenén chorava que queria mamá. Aí eu tomava um copo de suco antes, sempre antes, tudo antes, nada depois, se não enchia muito. $E$ também, chá. Sabe aquele do leão? Chá mate também pingava a noite inteira, mas a goiabada também ajudou muito...(M1)

A entrevistada M2 não acreditava nos lactogogos, porém fez uso de canjica, chá mate com leite, Malzebeer e Plasil. Em sua fala notamos a necessidade de uma ancoragem, seja alimentar ou social ...o que fez eu amamentar o bebê, mesmo, foi a persistência do meu marido... ... do primeiro bebê eu achava que canjica, talvez chá, fazer chá mate com leite, Malzebeer. Mas eu não acredito...(M2)

Discurso da M3, valorizando os alimentos (crença): ...fubá dá bastante leite... ...sopa de fubá além dela te dar substância... ...igual a sopa de fubá não tem... ...gema de ovo... ...canjica e bastante líquido... ...quando for dar de mamá, toma um copo de água, depois que dá o mamá... ...calda de frango... ...bastante canja... ...fruta... ...muito leite, tomá bastante liquido... ...canjica... (M3)

Pudemos perceber nas falas que há semelhança nos alimentos que elas ingeriram, portanto inferimos que a crença alimentar é cultural.

\section{Quem transmitiu}

É importante os profissionais de saúde oferecem orientação educacional às mulheres, já no início da gravidez e que estes sejam capazes de identificar mulheres que estejam correndo risco de enfrentar dificuldades no processo do aleitamento materno ${ }^{(4)}$.

Mulheres que recebem orientações de pessoas nas quais elas depositam total confiança apresentam mudança de comportamento ${ }^{(5)}$. E vimos que este fato ocorreu em nossa pesquisa. A mãe ainda exerce a função de eterna orientadora dos atos (tradição), apesar da nutriz ter constituído uma família, pois já vivenciou a maternidade. Assim como o médico exercendo um papel 
relevante na comunidade. Como veremos a seguir analisando as falas das entrevistadas ...minha mãe... ...foi o médico... (M1); ...minha mãe, né, os antigos... ...porque alguém falava ... ...porque a pessoa falava, eu fazia e acontecia... ...meu marido... ... uma amiga... (M2); ... a gente tinha mais liberdade com uma amiga... (M3)

\section{Validação do lactogogo}

No tocante à ingestão de líquidos foi comprovada pela experiência vivenciada pela mulher. Podemos inferir através dos dados obtidos que a mulher recebeu durante a lactação este aporte nutricional e calórico, conseqüentemente aumentando a produção do leite. Como demonstramos a seguir: Ah, porque eu senti, que o peito não estava tão cheio. Assim que eu tomava, parecia que o peito enchia mais de leite... ...eu só sei que tomava e descia, descia muito... (M1)

\section{Quando utilizou o lactogogo}

Verificamos que a utilização de lactogogo se deu no período de equilíbrio da lactação, podemos até inferir que talvez não tivesse ocorrido a hipogalactia ...na segunda semana que eu estava amamentando... (M1)

O surgimento da unidade temática III, APEGO, foi baseado em um questionamento: qual a diferença dos filhos que você amamentou dos filhos que você não amamentou?

No bebê o sentido mais evoluído é o tato, e este sente a necessidade de ser acariciado, amamentado e confortado. A boca é a primeira região do corpo na qual a criança manterá um contato cutâneo com a mãe $e^{(21)}$.

Da temática apego foram extraídos dois tópicos: tempo de aleitamento e relacionamento.

As entrevistadas demonstraram estes sentimentos nas seguintes falas: ...ela é muito ligada em mim... ...consegue um diálogo... ...não te cobra aquilo com agressão, ela tenta conversar com você. Agora a do meio... ...muito rebelde... ...agredia......a G... ...é muito mais amorosa e compreensiva...(M2); ...eu acho essencial mesmo o leite materno. (M3).

\section{Tempo de aleitamento}

O desmame inicia no momento em que se introduz alimentos sólidos, em torno dos seis meses de idade, às crianças sadias. Porém este período pode variar entre nove meses e três anos. 0 aleitamento materno além de fator nutricional é uma fonte de segurança para a criança ${ }^{(21)}$.

O período por nós detectados nas entrevistas foi variado: ...uma eu dei dois anos, a primeira e a segunda só seis meses..(M1); a primeira foi, é 40 dias, a segunda não tive, não amamentei e a terceira 1 ano e 1 mês..(M2); eu só não dei de mamar prá ela (M2) porque ela não quis... ...o segundo parto que foi os gêmeos, eles eu amamentei 3 meses...(M3)

\section{Relacionamento}

Como citado anteriormente, 0 aleitamento materno reafirma os laços mãe-bebê: ...ela é muito ligada em mim... ...você consegue um diálogo com ela... ela não te cobra aquilo com agressão, ela tenta conversar com você. Agora a do meio... ...na adolescência ela ficou muito rebelde.. (M2); ...eu acho essencial mesmo o leite materno. Porque quando você tá dando o leite materno, como eu pensei e vi que aconteceu com as minhas filhas e com a minha neta. Eu acho assim, que a criança que é alimentada com o peito......você percebe que são diferentes e a minha filha de gêmeos, também que amamentou, as crianças são bem diferentes...(M3)

Nomeamos a unidade IV, como o DECLÍNIO DO ALEITAMENTO, baseado na seguinte descrição "Desde o crepúsculo dos tempos as mulheres amamentavam suas crianças, quando de repente, no espaço de 60 anos, a mamadeira sai vencedora, conhecendo a preferência popular"(21).

O relato da entrevistada M3 retrata a citação acima: Porque as moças tinham menos vaidade. Hoje elas falam que cai os peitos....

Desta unidade temática surgiram quatro tópicos: vaidade, preguiça, praticicidade e compreensão.

\section{Vaidade, preguiça e praticicidade}

Muitas mulheres evitam amamentar pois temem engordar e ficar com as mamas caídas, porém há afirmativas de que é a gravidez que induz à deformidade das mamas e não a amamentação ${ }^{(21)}$. Quanto à preguiça, verifica-se uma controvérsia pois o aleitamento materno é a forma mais prática de se ter um leite pronto e em temperatura adequada, quando comparado ao preparo de uma mamadeira: $A$ vaidade e a preguiça, duas coisas que vai junto na moça de hoje... ...elas não tem coragem de ficar 15 minutos em um peito 15 no outro... ...elas acham uma loucura aquilo... ...não aceitam. É a vaidade das moças de hoje... ...eu acho que amamentar o neném não atrasa 0 serviço... ...se você for fazer mamadeira, e se for dar os peitos, não é mais fácil?... ... a criança grita de fome, você joga uma fralda nos peitos e dá... ...você não precisa ficar carregando sacola.......eva três quatro mamadeiras, em todo lugar que você vai azeda estraga...(M3).

\section{Compreensão}

A incapacidade de aleitar nos países industrializados está associada a pouca informação e experiência sobre a amamentação ${ }^{(20)}$.

O nível social determina o hábito. A necessidade de retornar 
ao trabalho não é causa para iniciar o desmame precoce. Os fatores que levam ao maior tempo de aleitamento materno estão associados a " maior acesso à informação e à atenção médica nos grupos sociais mais privilegiados" ${ }^{\prime \prime 22)}$.

A amamentação "...é uma escolha individual que se desenvolve dentro de um contexto sociocultural, portanto influenciada pela sociedade e pelas condições de vida da mulher"(5).

A fala da M3 retrata a citação bibliográfica traçada acima: porque elas não entendem... ...já casam, já querem uma televisão, um freezer, uma geladeira, um microondas. Elas querem tudo ali, elas exigem.. ... elas não põe na cabeça a saúde que seria dar de mamá... ...modernismo de hoje, não adianta...

\section{CONSIDERAÇÕES FINAIS}

O aleitamento materno além de ser biológico é histórico, social e psicologicamente delineado, estando a cultura, a crença e os tabus influenciando de forma crucial a sua prática, interferindo na construção de uma herança sociocultural e determinando diferentes

\section{REFERÊNCIAS BIBLIOGRÁFICAS}

1. Organização Mundial da Saúde (OMS) Lactação. In: Organização Mundial da Saúde (OMS) Alimentação infantil bases fisiológica. São Paulo (SP): IBFAN Brasil e Instituto de Saúde, OMS, OPAS e UNICEF Brasil; 1994. p. 17-35.

2. Ricco RG. Aleitamento natural. In: Woiski JR. Nutrição e dietética em pediatria. 4 ed. São Paulo (SP): Atheneu; 1995. p. 55-88.

3. Gesteira M. O problema da hipogalactia. Indicações da amamentação mercenária. Indicações e técnica da alimentação mista. In: Gesteira M. Puericultura 3 ed. Rio de Janeiro (RJ): Panamericana; 1957. p.114 -130.

4. UNICEF/MS. Programa Nacional de Incentivo ao Aleitamento Materno. Grupo de Defesa da Saúde da Criança. Manejo e promoção do aleitamento materno. Brasília (DF): OMS/OPAS/UNICEF; 1993.

5. Bitar MAF. Aleitamento materno: um estudo etnográfico sobre os costumes crenças e tabus ligados a esta prática. [dissertação]. Belém (PA): Centro de Ciências da Saúde Departamento de Enfermagem/ Universidade Federal do Pará; 1995.

6. Dicionário Aurélio básico da língua portuguesa. Rio de Janeiro: Nova Fronteira; 1988. Crença; p.186.

7. Dicionário Aurélio básico da língua portuguesa. Rio de Janeiro: Nova Fronteira; 1988. Fé; p.292.

8. Dicionário Aurélio básico da língua portuguesa. Rio de Janeiro: Nova Fronteira; 1988. Mitos; p.436. significados ao aleitamento materno para a mulher. Desta maneira, levando a amamentar ou não o seu bebê, alimentar-se ou não de determinados alimentos no puerpério. Ter vivenciado a amamentação, crenças transmitidas por familiares, orientações médicas, crescimento e desenvolvimento da criança foram os fatores que estimularam 0 aleitamento materno nesse estudo. Constatamos que as mulheres fizeram uso de lactogogos/galactogogos frente a hipogalactia, acreditavam no seu uso como um dos suportes ao aleitamento materno, e mantinham a crença fundamentada nas informações transmitidas culturalmente através do relacionamento avó-mãe-filha. Utilizaram como lactogogos frutas, suco, Plasil, leite, sopa de fubá, carne branca, couve, queijo, goiabada, chá mate, canjica, Malzebeer, gema de ovo, caldo de frango, canja e enfatizaram muito a necessidade da ingestão de líquidos.

Ainda que existam estudos quanto a nutrição da lactante no período da lactogênese, sugerimos que sejam realizadas pesquisas para comprovar como e por quê a canjica, as frutas e demais alimentos citados pelas mulheres, aumentam a produção do leite, embora saibamos que 0 aleitamento materno sofre influências multidimensionais ou seja bio, psico, histórico e sóciocultural.

9. Dicionário Aurélio básico da língua portuguesa. Rio de Janeiro: Nova Fronteira; 1988. Tradição; p.643.

10. Trivinõs ANS. Pesquisa qualitativa. In: Trivinõs ANS. Introdução à pesquisa em ciências sociais: a pesquisa qualitativa em educação. São Paulo (SP): Atlas; 1990. p.116-173.

11. Alberti V. História oral: a experiência do CPDOC. Rio de Janeiro (RJ): Fundação Getúlio Vargas; 1989.

12. André MCDA. Texto, contexto e significados: algumas questões na análise de dados qualitativos. Cad Pesqui 1983 maio;45:66-71.

13. Silva AAM. Amamentação: fardo do desejo? Estudo histórico social dos deveres e práticas sobre aleitamento na sociedade brasileira. [dissertação]. Ribeirão Preto (SP): Faculdade de Medicina de Ribeirão Preto/USP; 1990.

14. Vinha VHP, Scochi CGS. Aleitamento materno - evolução histórica. Femina 1989 outubro;17(10):819-23

15. Ornellas LH. Alimentação na idade antiga In: Ornellas LH. A alimentação através dos tempos. Rio de Janeiro (RJ): FENAME; 1978. p.9-49.

16. Kauppila A, Anunti P, Kivinen S, Koivisto M, Ruokonen A. Metoclopramide and breas feeding: efficacy and anterior pituitary responses of the mother and the child. Eur J Obstet Gynecol Reprod Biol 1985 January;19(1):19-22. 
17. Ornellas A, Ornellas LH. Alimentação da lactante. In: Ornellas A, Ornellas LH. Alimentação da criança. 2 ed. São Paulo (SP): Atheneu; 1983. p.439-43.

18. Mitchell HS, Anderson L, Dibble MV. Nutrição na gestação e na lactação. In: Mitchell HS, Anderson L, Dibble MV. Nutrição. 16 ed. Rio de Janeiro (RJ): Interamericana; 1978. p. 232-43.

19. Burton BT. Nutrição na gravidez e lactação. In: Burton BT. Nutrição humana. Rio de Janeiro (RJ): Mc Graw Hill; 1979. p.203-12.
20. Organização Mundial da Saúde (OMS) Fatores de saúde que podem interferir na amamentação. In: Organização Mundial da Saúde (OMS) Alimentação infantil bases fisiológica. São Paulo (SP): IBFAN Brasil e Instituto de Saúde, OMS, OPAS e UNICEF Brasil; 1994. p.3948.

21. Clark C. O livro do aleitamento materno. 2. ed. São Paulo (SP): Manole; 1984.

22. Bouer J. Nível social determina hábito. Folha de São Paulo [online]. [acessado em 11 Agosto 1996]. Disponível em: URL: http:// www.uol.com.br/saude/noticiar/s110896g.htm 